\title{
Loss of expression and prognosis value of alpha-internexin in gastroenteropancreatic neuroendocrine neoplasm
}

\author{
Yuhong Wang ${ }^{1}$, Yuanjia Chen ${ }^{2}$, Xiaoxing $\mathrm{Li}^{3}$, Wanming Hu${ }^{4}$, Yu Zhang ${ }^{1}$, Luohai Chen ${ }^{1}$, Minhu Chen ${ }^{1 *+}$ \\ and Jie Chen ${ }^{1 *+}$
}

\begin{abstract}
Background: The neuronal intermediate filament alpha-internexin (a-internexin) is a cytoskeleton protein which is involved in the tumor initiation and progression. In this study, we examined the expression and prognosis value of a-internexin in gastroenteropancreatic neuroendocrine neoplasms (GEP-NENs).

Methods: a-internexin was detected with immunohistochemical staining in 286 tumor specimens from patients with GEP-NENs. Methylation status of $a$-internexin was evaluated by bisulfite genomic sequencing. We assessed the prognostic value of a-internexin and its correlation with relevant clinicalpathological characteristics.

Results: The reduced/loss of expression rate of a-internexin in GEP-NEN was 73.4\% (210/286), while the positive expression rate was $26.6 \%$ (76/286). The difference of a-internexin deficiency was not statistically significant between gastrointestinal NENs (GI-NENs) and pancreatic NENs (pNENs). However, we found significant difference of reduced/loss of a-internexin expression among different sites of GI-NENs $\left(X^{2}=43.470, P<0.001\right)$. The reduced/loss of expression of a-internexin was significantly associated with poorly differentiation $(P<0.001)$ and advanced tumor stage $(P<0.001)$. Univariate analyses showed that reduced/loss of expression of a-internexin predicted worse overall survival (OS) in GEP-NEN patients $(P<0.001)$, especially in subtype of GI-NENs $(P<0.001)$. However, in multivariable regression analysis, $a$-internexin expression was not an independent prognostic factor. The hypermethylation of $a$ internexin gene was significantly correlated with protein deficiency in GI-NENs, but not in pNENs. Hypermethylation of several CpG sites was significantly associated with poorly differentiated and advanced stage ( $P$ values range from 0.018 to 0.044$)$. However, the methylation status of a-internexin was not associated with patient OS.

Conclusions: The expression of a-internexin was highly heterougeneous in different sites of GEP-NENs. The reduced/loss of expression of a-internexin was closely related to tumors with aggressiveness and patient's adverse prognosis. The hypermethylation of the regulatory region examined may be an important epigenetic regulation mechanism of a-internexin deficiency in subtype of GI-NENs.
\end{abstract}

Keywords: Gastroenteropancreatic neuroendocrine neoplasm. Alpha-internexin. Expression. Prognosis

\footnotetext{
* Correspondence: chenminhu@mail.sysu.edu.cn; chen0jie@hotmail.com ${ }^{\dagger}$ Minhu Chen and Jie Chen contributed equally to this work.

${ }^{1}$ Department of Gastroenterology, The First Affiliated Hospital, Sun Yat-sen University, No.58 Zhongshan II Road, Yuexiu District, Guangzhou 510080, China

Full list of author information is available at the end of the article
}

(c) The Author(s). 2018 Open Access This article is distributed under the terms of the Creative Commons Attribution 4.0 International License (http://creativecommons.org/licenses/by/4.0/), which permits unrestricted use, distribution, and reproduction in any medium, provided you give appropriate credit to the original author(s) and the source, provide a link to the Creative Commons license, and indicate if changes were made. The Creative Commons Public Domain Dedication waiver (http://creativecommons.org/publicdomain/zero/1.0/) applies to the data made available in this article, unless otherwise stated. 


\section{Background}

Gastroenteropancreatic neuroendocrine neoplasms (GEP-NENs), which originate from neuroendocrine cells distributed throughout the digestive system, comprise a heterogeneous family with wide and complex clinical behaviors. They are often associated with a very aggressive clinical course and $60 \% \sim 80 \%$ of NENs are metastatic when identified, although being generally more indolent than carcinomas [1]. At present, only few reliable molecular biomarkers could predict the biological behavior and prognosis of the patients with GEP-NEN [2, 3]. Therefore, searching for novel biomarkers is an important issue on GEP-NEN.

Alpha-internexin is a $66-\mathrm{kDa}$ type IV intermediate filament protein. As a cytoskeleton protein, previous studies showed that it is mainly expressed in various kinds of central and peripheral neurons from early development [4], and is frequently detected in medulloblastomas [5] and neuroblastomas which shared some common features with neuroendocrine tumors [6]. Previous several studies have detected the expression of $\alpha$-internexin on particular types of GEP-NENs such as well-differentiated endocrine tumors, or a single site of tumors (pancreas, small intestinal, appendix or rectum). These studies reported the expression of $\alpha$-internexin varied from different sites of GEP-NEN. They also made inconsistent conclusions on the relationship between $\alpha$-internexin expression and tumor biological behavior [7-9]. Therefore, the expression of $\alpha$-internexin and its clinical and prognosis value in GEP-NEN is worth of investigation.

In the current study, we determined the expression of $\alpha$ internexin in a large cohort of GEP-NEN using immunohistochemistry and findings were associated with clinicopathological variables and patient prognosis. We further investigated the regulation of the epigenetic mechanisms of $\alpha$-internexin gene expression, and explored the clinical and prognostic role of $\alpha$-internexin methylation in GEP-NEN. In addition, previous studies revealed that GEP-NEN is a type of tumor with marked heterogeneity. Tumors originated from gastrointestinal tract may considerably differ from those from pancreas [1]. Therefore, the analyses were performed not only in GEP-NEN as a whole, but also in gastrointestinal NENs (GI-NENs) and pancreatic NENs (pNENs) as separate subgroup in this study.

\section{Methods}

\section{Patients information}

A total of 286 patients with histologically confirmed sporadic GEP-NEN in The First Affiliated Hospital, Sun Yatsen University from September 2002 to December 2014 were enrolled in the study to determine the expression of $\alpha$-internexin. The methylation status of $\alpha$-internexin was evaluated by bisulfite genomic sequencing (BGS) in 116 cases out of 286 patients. Patients' clinicopathologic characters are summarized in Table 1 and Table 2.

A functional tumor was defined as overproducing a hormone such as 5-hydroxytryptamine, gastrin, glucagon, insulin, somatostatin and vasoactive intestinal peptide, which causes clinical symptoms. The pathology of each patient was reviewed by a pathologist (Wanming $\mathrm{Hu}$ ) according to the 4th edition World Health Organization classification of tumors of the digestive system [10]. Tumor-Node-Metastasis (TNM) stage was adopted according to the European Neuroendocrine Tumor Society Consensus Guidelines [11, 12] in tumors originated from the gastrointestinal tract, pancreas and metastatic NENs of unknown primary. Other sites included esophagus, biliary tract were classified by 2017 American Joint Committee on Cancer Staging Atlas 8th edition [13].

\section{Immunohistochemistry}

To detect the expression of $\alpha$-internexin in GEP-NEN tissues, immunohistochemical studies were performed on paraffin sections using an EnVision method. Sections of tumor specimens (4 $\mu \mathrm{m}$ thick) from formalin-fixed paraffinembedded were used for immunohistochemical examinations. The slides were dewaxed with xylene, rehydrated in a graded series of ethanol. Heat-induced epitope retrieval was done using a pressure cooker at $1000 \mathrm{~W}$ for $2.5 \mathrm{~min}$ in preheated Tris-EDTA buffer ( $\mathrm{pH}$ 9.0). Endogenous peroxidase activity was blocked by incubating the slides in 3\% hydrogen peroxide for $20 \mathrm{~min}$ at room temperature. The slides were transferred to phosphate-buffered saline and then incubated at $4{ }^{\circ} \mathrm{C}$ with rabbit monoclonal anti- $\alpha$-internexin (1:400; MAB5224; Millipore, Darmstadt, Germany) overnight. In the second day, sections were incubated in secondary antibody (Real EnVision Detection kit, ready-touse; K5007; Dako; Agilent Technologies, Inc., Santa Clara, CA, USA) for $1 \mathrm{~h}$ at room temperature. The substrate chromogen, 3.3' -diaminobenzidine, enabled visualization of the complex via a brown precipitate. Hematoxylin (blue) counterstaining enabled the visualization of the cell nuclei with a light microscope (4500; Olympus Corporation, Tokyo, Japan). Omission of primary antibody served as a negative control.

\section{Histological interpretation}

The $\alpha$-internexin positive staining refers to cytoplasm staining to yellow or dark brown. Nonneoplastic cells (lymphocytes, stromal cells, endothelial cells and liver cells) served as an internal positive control in all tissue sections. The criteria [7] of semi-quantitative grading of IHC: (-) means no positive staining in tumor cells; $( \pm)<20 \%$ tumor cells showing positive staining; $(+) \geq 20 \%$ but $<50 \%$ tumor cells showing positive staining; $(++) \geq 50 \%$ but $<75 \%$ tumor cells shown positive staining; $(+++) \geq 75 \%$ tumor cells shown positive staining. We defined $<20 \%$ tumor cells 
Table 1 Clinicopathological characteristics of patients with a-internexin immunohistochemical detection

\begin{tabular}{|c|c|c|c|}
\hline \multicolumn{2}{|c|}{ Demographic and Clinical Characteristics } & $\mathrm{N}$ & $\%$ \\
\hline \multicolumn{4}{|l|}{ GEP-NENs $(n=286)$} \\
\hline \multirow[t]{2}{*}{ Sex } & Male & 173 & 60.5 \\
\hline & Female & 113 & 39.5 \\
\hline \multirow{3}{*}{$\begin{array}{l}\text { Age (years) at } \\
\text { diagnosis }\end{array}$} & $\leq 50$ & 134 & 46.9 \\
\hline & $>50$ & 152 & 53.1 \\
\hline & Median (range) & $\begin{array}{l}53(16- \\
85)\end{array}$ & \\
\hline \multirow[t]{7}{*}{ Functional status } & Nonfunctional & 234 & 81.8 \\
\hline & Functional & 52 & 18.2 \\
\hline & Insulinoma & 42 & 14.7 \\
\hline & $\begin{array}{l}\text { Vasoactive intestinal } \\
\text { polypeptidoma }\end{array}$ & 7 & 2.4 \\
\hline & Carcinoid syndrome & 1 & 0.3 \\
\hline & Somatostatinoma & 1 & 0.3 \\
\hline & Gastrinoma & 1 & 0.3 \\
\hline \multirow[t]{13}{*}{ Tumor location } & Gastrointestinal tract & 162 & 56.6 \\
\hline & Rectum & 60 & 21.0 \\
\hline & Stomach & 43 & 15.0 \\
\hline & Duodenum & 21 & 7.3 \\
\hline & Esophagus & 18 & 6.3 \\
\hline & Jejunum/ileum & 9 & 3.1 \\
\hline & Appendix & 6 & 2.1 \\
\hline & Colon & 5 & 1.7 \\
\hline & Pancreas & 93 & 32.5 \\
\hline & Other & 31 & 10.8 \\
\hline & $\begin{array}{l}\text { Metastasis of unknown } \\
\text { primary }\end{array}$ & 25 & 8.7 \\
\hline & Biliary tract & 5 & 1.7 \\
\hline & Greater omentum & 1 & 0.3 \\
\hline \multirow[t]{3}{*}{ Tumor grade ${ }^{a}$} & G1 & 120 & 43.2 \\
\hline & G2 & 57 & 20.5 \\
\hline & G3 & 101 & 36.3 \\
\hline \multirow[t]{6}{*}{ Tumor type ${ }^{a}$} & NET & 180 & 64.7 \\
\hline & NET G1 & 120 & 43.2 \\
\hline & NET G2 & 57 & 20.5 \\
\hline & NET G3 & 3 & 1.1 \\
\hline & NEC & 91 & 32.7 \\
\hline & MANEC & 7 & 2.5 \\
\hline \multirow[t]{4}{*}{ Tumor stage } & । & 79 & 27.6 \\
\hline & $\|$ & 61 & 21.3 \\
\hline & III & 45 & 15.7 \\
\hline & IV & 101 & 35.3 \\
\hline
\end{tabular}

GI-NENs $(n=162)$

Tumor grade

G1
Table 1 Clinicopathological characteristics of patients with a-internexin immunohistochemical detection (Continued)

\begin{tabular}{|c|c|c|c|}
\hline \multicolumn{2}{|c|}{ Demographic and Clinical Characteristics } & \multirow{2}{*}{$\frac{N}{21}$} & \multirow{2}{*}{$\frac{\%}{13.5}$} \\
\hline & G2 & & \\
\hline & G3 & 75 & 48.1 \\
\hline \multirow[t]{5}{*}{ Tumor type } & NET & 81 & 51.9 \\
\hline & NET G1 & 60 & 38.5 \\
\hline & NET G2 & 21 & 13.5 \\
\hline & NEC & 70 & 44.9 \\
\hline & MANEC & 5 & 3.2 \\
\hline \multirow[t]{4}{*}{ Tumor stage } & । & 48 & 29.6 \\
\hline & $\|$ & 26 & 16.0 \\
\hline & III & 37 & 22.8 \\
\hline & IV & 51 & 31.5 \\
\hline \multicolumn{4}{|l|}{ pNENs $(n=93)$} \\
\hline \multirow[t]{3}{*}{ Tumor grade ${ }^{c}$} & G1 & 54 & 59.3 \\
\hline & G2 & 27 & 29.7 \\
\hline & G3 & 10 & 11.0 \\
\hline \multirow[t]{6}{*}{ Tumor type ${ }^{c}$} & NET & 84 & 92.3 \\
\hline & NET G1 & 54 & 59.3 \\
\hline & NET G2 & 27 & 29.7 \\
\hline & NET G3 & 3 & 3.3 \\
\hline & NEC & 7 & 7.7 \\
\hline & MANEC & 0 & 0 \\
\hline \multirow[t]{4}{*}{ Tumor stage } & I & 30 & 32.3 \\
\hline & $\|$ & 30 & 32.3 \\
\hline & III & 4 & 4.3 \\
\hline & IV & 29 & 31.2 \\
\hline
\end{tabular}

a 278 cases both for tumor grade and tumor type; ${ }^{\mathrm{b}} 156$ cases both for tumor grade and tumor type; ${ }^{\mathrm{C}}$ 91cases both for tumor grade and tumor type GEP-NEN Gastroenteropancreatic neuroendocrine neoplasm, NET

Neuroendocrine tumor, NEC Neuroendocrine carcinoma, MANEC Mixed adenoneuroendocrine carcinoma, GI-NEN Gastrointestinal neuroendocrine neoplasm, pNEN Pancreatic neuroendocrine neoplasm

with staining of $\alpha$-internexin as reduced or loss of (reduced/loss of) expression, and otherwise defined as positive. All slides were evaluated independently by Wanming $\mathrm{Hu}$ who was blinded to the patients' clinical data.

\section{Bisulfite genomic sequencing}

Genomic DNA was extracted from 116 GEP-NEN tissues using QIAamp DNA FFPE Tissue Kit (56404; Qiagen, Hilden, Germany) and treated with sodium bisulfite using an EZ DNA Methylation-Gold Kit (D5006; Zymo Research, Orange, CA, USA). The bisulfitemodified DNA was amplified using primer pairs (Forward: 5' - GATTTGGAGAAGAAGGTGGAGT-3', Reverse: 5 '-TGATTGTGGTTAAATTAGAT TTGAT-3') that specifically amplify the region $(+683 \sim+834)$ relative to the transcription start site (TSS) of $\alpha$-internexin. 
Table 2 Clinicopathological characteristics of patients with a-internexin methylation

\begin{tabular}{|c|c|c|c|}
\hline Demographic and $\mathrm{Cl}$ & al Characteristics & N & $\%$ \\
\hline GEP-NENs $(n=116)$ & & & \\
\hline Sex & Male & 72 & 62 \\
\hline & Female & 44 & 37 \\
\hline Age (years) at & $\leq 50$ & 50 & 43 \\
\hline & $>50$ & 66 & 56 \\
\hline & Median (range) & $\begin{array}{l}55(16- \\
83)\end{array}$ & \\
\hline Functional status & Nonfunctional & 89 & 76 \\
\hline & Functional & 27 & 23 \\
\hline & Insulinoma & 26 & 22 \\
\hline & Gastrinoma & 1 & 0. \\
\hline Tumor location & Gastrointestinal tract & 54 & 46 \\
\hline & Stomach & 18 & 15 \\
\hline & Rectum & 10 & 8. \\
\hline & Duodenum & 10 & 8. \\
\hline & Esophagus & 10 & 8. \\
\hline & Colon & 4 & 3. \\
\hline & Jejunum/ileum & 2 & 1.7 \\
\hline & Pancreas & 49 & 42 \\
\hline & Other & 13 & 11 \\
\hline & $\begin{array}{l}\text { Metastasis of unknown } \\
\text { primary }\end{array}$ & 10 & 8. \\
\hline & Biliary tract & 3 & 2.6 \\
\hline Tumor grade ${ }^{a}$ & G1 & 41 & 36 \\
\hline & G2 & 23 & 20 \\
\hline & G3 & 49 & 43 \\
\hline Tumor type $^{a}$ & NET & 64 & 56 \\
\hline & NET G1 & 41 & 36 \\
\hline & NET G2 & 23 & 20 \\
\hline & NEC & 43 & 38 \\
\hline & MANEC & 6 & 5.3 \\
\hline Tumor stage & I & 27 & 23 \\
\hline & $\|$ & 35 & 30 \\
\hline & III & 28 & 24 \\
\hline & IV & 26 & 22 \\
\hline
\end{tabular}

Gl-NENs $(n=54)$

Tumor grade

$\begin{array}{cl} & \text { G2 } \\ & \text { G3 } \\ \text { Tumor type }^{b} & \text { NET } \\ & \text { NET G1 } \\ \text { NET G2 } \\ \text { NEC }\end{array}$

Table 2 Clinicopathological characteristics of patients with a-internexin methylation (Continued)

\begin{tabular}{|c|c|c|c|}
\hline \multicolumn{2}{|c|}{ Demographic and Clinical Characteristics } & \multirow{2}{*}{$\frac{N}{4}$} & \multirow{2}{*}{$\frac{\%}{7.7}$} \\
\hline & MANEC & & \\
\hline \multirow[t]{4}{*}{ Tumor stage } & । & 5 & 9.3 \\
\hline & $\|$ & 14 & 25.9 \\
\hline & III & 23 & 42.6 \\
\hline & IV & 12 & 22.2 \\
\hline \multicolumn{4}{|l|}{ pNENs $(n=49)$} \\
\hline \multirow[t]{3}{*}{ Tumor grade ${ }^{c}$} & G1 & 32 & 66.7 \\
\hline & G2 & 11 & 22.9 \\
\hline & G3 & 5 & 10.4 \\
\hline \multirow[t]{5}{*}{ Tumor type ${ }^{c}$} & NET & 43 & 89.6 \\
\hline & NET G1 & 32 & 66.7 \\
\hline & NET G2 & 11 & 22.9 \\
\hline & NEC & 5 & 10.4 \\
\hline & MANEC & 0 & 0 \\
\hline \multirow[t]{4}{*}{ Tumor stage } & 1 & 22 & 44.9 \\
\hline & $\|$ & 20 & 40.8 \\
\hline & III & 1 & 2.0 \\
\hline & IV & 6 & 12.2 \\
\hline
\end{tabular}

a 113 cases both for tumor grade and tumor type; ${ }^{\mathrm{b}} 52$ cases both for tumor grade and tumor type; ${ }^{c} 48$ cases both for tumor grade and tumor type GEP-NEN: Gastroenteropancreatic neuroendocrine neoplasm; NET:

Neuroendocrine tumor; NEC: Neuroendocrine carcinoma; MANEC: Mixed adenoneuroendocrine carcinoma; GI-NEN: Gastrointestinal neuroendocrine neoplasm; pNEN: Pancreatic neuroendocrine neoplasm

A total volume of PCR amplification mixture was $25 \mu \mathrm{l}$ containing $1 \mu \mathrm{l}$ DNA, $1 \mu \mathrm{l}$ of each primer, $12.5 \mu \mathrm{l}$ Zymo Taq Premix (E2003; Zymo Research, Orange, CA, USA) and $6.5 \mu \mathrm{l}$ water. PCR was run in Verti Thermal cycler (Applied Biosystems, Foster City, CA, USA). The PCR cycling parameters were as follows: denaturing of $95{ }^{\circ} \mathrm{C}$ (10 min); then 42 cycles of $95{ }^{\circ} \mathrm{C}(30 \mathrm{~s}), 56{ }^{\circ} \mathrm{C}(40 \mathrm{~s}), 72{ }^{\circ} \mathrm{C}$ (40s); a final elongation step of $72{ }^{\circ} \mathrm{C}(7 \mathrm{~min})$. The target fragment was $152 \mathrm{bp}$ in length containing fifteen $\mathrm{CpG}$ sites: GATTTGGAGAAGAA GGTGGAGTCGTTGTTGGACGAGTTGGTTTTCGTACGTTAGGTGTACGACGAGGA GGTAGTCGAGTTGTTGGTTACGTTGTAGGCGTCGT CGTAGGTCGCGGTCGAGGTGGACGTGATTGTGGT TAAATTAGATTTGAT (Each vertical bar represents a single CpG site). PCR products were sequenced by the BGI Science and Technology, Ltd. (Guangzhou) Research Center. When analyzed, due to the former three CpG sites (included in the $+705 \sim+728$ region) couldn't provide exactly methylation level, we analyzed the rest of $12 \mathrm{CpG}$ sites (included in the $+729 \sim+834$ region) in this study. Each CpG site was recorded as $S_{1}, S_{2}, S_{3} \ldots S_{12}$. Methylation percentage was calculated according to the formula: methylation $\%=H_{\mathrm{C}} /\left(H_{\mathrm{C}}+H_{\mathrm{T}}\right) \times 100 \% \quad\left(H_{\mathrm{C}}=\right.$ height of peak $\mathrm{C}$ and $H_{\mathrm{T}}=$ height of peak $\left.\mathrm{T}\right)$. Accordingly, average 
methylation percentage of total $12 \mathrm{CpG}$ sites was calculated by the formula: methylation\% $=\left[H_{\mathrm{C} 1} /\left(H_{\mathrm{C} 1}+H_{\mathrm{T} 1}\right)+\right.$ $\left.H_{\mathrm{C} 2} /\left(H_{\mathrm{C} 2}+H_{\mathrm{T} 2}\right) \ldots+H_{\mathrm{C} 12} /\left(H_{\mathrm{C} 12}+H_{\mathrm{T} 12}\right)\right] / 12 \times 100 \%$.

\section{Statistical analysis}

Statistical analyses were performed using SPSS version 23.0 (IBM, Chicago, IL). Descriptive statistics of qualitative data such as patient's general data, positive expression rates, were expressed as numbers and percentages. The association of $\alpha$-internexin expression with various clinicopathologic features was analyzed using Pearson chi-square test. The correlation between $\alpha$-internexin methylation status and $\alpha$-internexin protein expression level, patient's clinicopathologic features were estimated by Mann-Whitney or Kruskal-Wallis test. Receiver operating characteristic (ROC) curve was used to estimate the cutoff value of the methylation percentage. Overall survival (OS) analyses were performed using the Kaplan-Meier cureves and log-rank test. Multivariate analyses were performed using Cox proportional hazards regression by including variables that were significantly associated with survival in logrank test. Hazard ratios (HRs) and 95\% confidence intervals (CIs) were calculated. A two-sided $P$ value of $<0.05$ indicates statistically significance.

\section{Results}

Immunohistochemical expression of a-internexin in GEPNEN

As shown in Fig. 1, $\alpha$-internexin was positively immunostained in the cytoplasm of tumor cells, and varied from weak-incomplete to strong-complete. No nuclear immunostaining was observed. The reduced/loss of expression rate of $\alpha$-internexin was $73.4 \%(210 / 286)$, while the positive expression rate was $26.6 \%(76 / 286)$. The reduced/loss of expression of $\alpha$-internexin was significantly higher in nonfunctional tumors than in those with hormonal syndrome $\left(76.5 \%\right.$ vs. $\left.59.6 \% ; X^{2}=6.213, P=0.013\right)$. The $\alpha$ internexin deficiency was not statistically different between GI-NENs and pNENs (76.5\% vs. $67.7 \%$; $P=0.126)$. However, different sites in GI-NENs had significant different frequency of $\alpha$-internexin deficiency $\left(x^{2}=43.470, P<0.001\right)$. Tumor sites with the highest reduced/loss of expression percentages of $\alpha$-internexin included esophagus (18/18, $100 \%)$ and jejunum/ileum $(9 / 9,100 \%)$, followed by stomach (42/43, 97.7\%), duodenum (17/21, 81.0\%), colon (4/5, 80. $0 \%)$, rectum $(32 / 60,53.3 \%)$ and appendix $(2 / 6,33.3 \%)$.

\section{Correlation of a-internexin expression with tumor grade, type and stage}

In patients with GEP-NENs, the reduced/loss of expression of $\alpha$-internexin in tumors graded as G1, G2 and G3 were
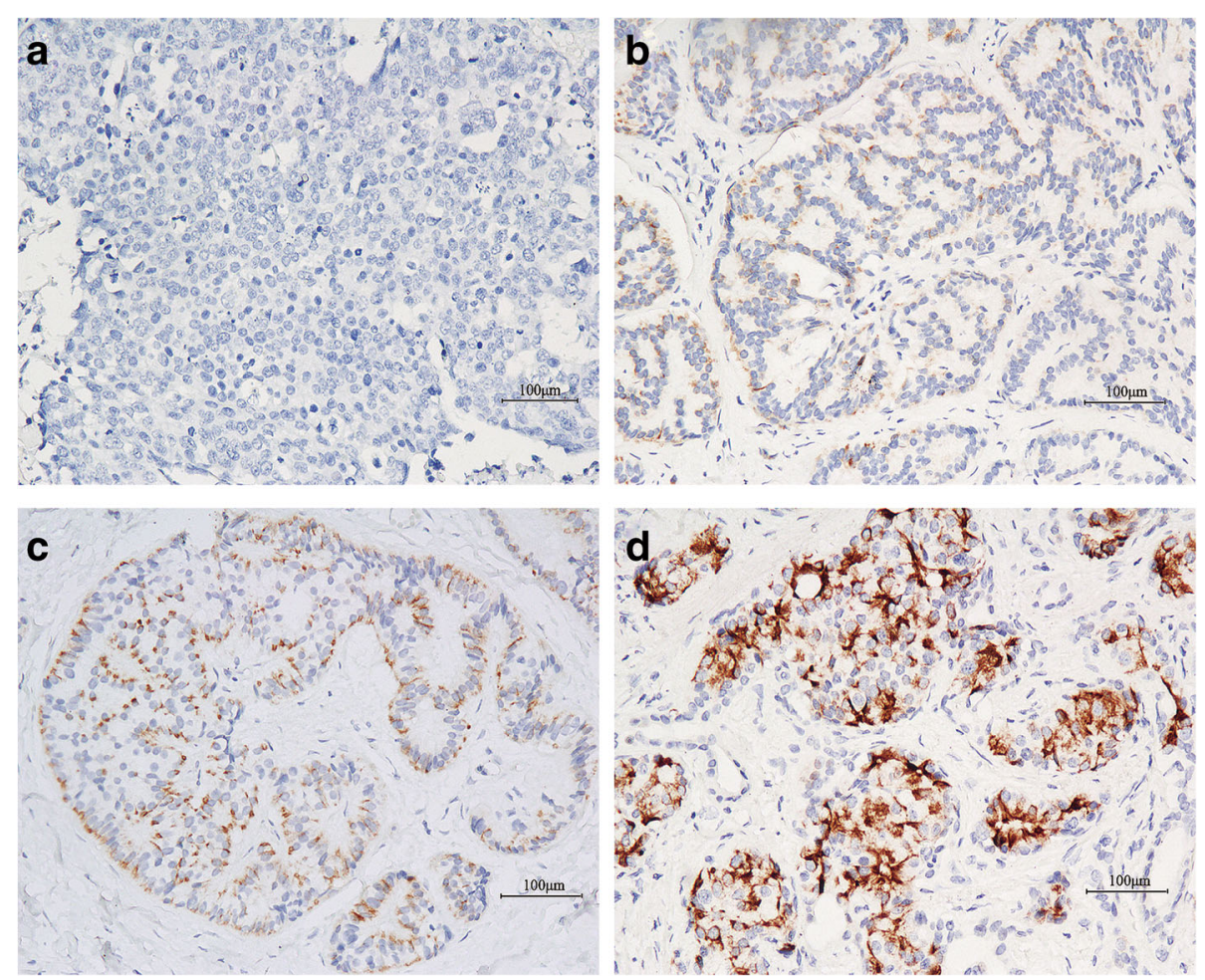

Fig. $1 \mathrm{lmm}$ unohistochemical staining of a-internexin in gastroenteropancreatic neuroendocrine neoplasm (using the EnVision method). a Gastric NEC, G3, negative staining. b Rectal NET, G1, weak positive staining. c Rectal NET, G1, moderate positive staining. d Pancreatic NET, G1, strong positive staining. Magnification, $\times 20$. NET: Neuroendocrine tumor; NEC: Neuroendocrine carcinoma 
57.5, 63.2 and 98.0\%, respectively $\left(x^{2}=49.934, P<0.001\right)$. In addition, reduced/loss of expression of $\alpha$-internexin was also significantly higher in poorly differentiated neuroendocrine carcinoma (NEC) and mixed adenoendocrine carcinoma (MANEC) than in well differentiated neuroendocrine tumor (NET) $\left(98.0 \%\right.$ vs. $\left.60.0 \% ; X^{2}=46.807, P<0.001\right)$. The reduced/loss of expression rate of $\alpha$-internexin in tumors of stage III + IV was $87.0 \%$, which was significantly higher than that of stage I + II (59.3\%; $\left.\chi^{2}=28.106, P<0.001\right)$.

In subtype of GI-NENs, tumors graded as G3 and classified as NEC + MANEC had higher $\alpha$-internexin reduced/loss of expression percentages than G1, G2 and NET (both $P<0.001$ ). $\alpha$-internexin deficiency was also significantly higher in tumors of stage III + IV than in stage I + II $\left(X^{2}=25.786, P<0.001\right)$.

In subtype of pNENs, the reduced or loss of expression of $\alpha$-internexin was associated with advanced stage $\left(x^{2}=\right.$ 4.638, $P=0.031)$, but not correlated with tumor grade or tumor type $(P=0.231$ and $P=0.299$, respectively).

The correlation of $\alpha$-internexin expression with patient's characteristics is summarized in Table 3.

\section{Correlation of a-internexin expression with overall survival}

253 out of 286 patients received long-term follow up with a median duration of 3.59 years (range 0.02-14.6 years). At the last follow-up, 86 patients (34.0\%) had died: four died of postoperative complications or other diseases and 82 from tumor progression. Only NEN-related deaths were considered as events for survival analysis.

In patients with GEP-NENs, Kaplan-Meier survival curves showed that the mean overall survival time of patients with reduced/loss of expression of $\alpha$-internexin was 8.6 years, while those with positive expression was 13.2 years (Fig. $2 \mathrm{a} ; X^{2}=21.968, P<0.001$ ). Multivariable analysis demonstrated that $\alpha$-internexin was not an independent prognostic marker (HR 0.770, 95\% CI 0.2981.985, $P=0.588$ ). Expectedly, tumor grade and TNM stage were independently associated with overall survival ( $P=0.019$ and $P<0.001$, respectively).

GI-NEN patients with reduced/loss of expression of $\alpha$-internexin had poorer survival than those with positive expression (Fig. 2b; mean OS: 8.2 years vs. 11 . 3 years; $\left.X^{2}=16.094, P<0.001\right)$. However, multivariable Cox's model demonstrated that $\alpha$-internexin was not an independent predictor of survival (HR 1.303, 95\% CI $0.241-7.058, \quad P=0.759)$. $\alpha$-internexin deficiency was not significantly associated with $O S$ in patients with pNEN (Fig. 2c; $\chi^{2}=1.850, P=0.174$ ). Tumor grade, tumor type and TNM stage were independent prognostic factors both in subtype of GI-NENs and pNENs. The results of multivariate Cox proportional hazard model are provided in Table 4 .

\section{Correlation of $a$-internexin methylation status with its protein expression}

Methylation status of $\alpha$-internexin was detected by BGS in 116 cases (Fig. 3)The median methylation percentage of total CpG sites was similar between tumors with positive $\alpha$-internexin expression and those without $\alpha$ internexin expression $(64.1 \%$ vs. $65.8 \%$; $P=0.091)$. We further analyzed the correlation of methylation level of each CpG site with $\alpha$-internexin expression. The methylation level of $\mathrm{CpG} \mathrm{S}_{4}$ and $\mathrm{S}_{6}$ were both significantly higher in tumors with $\alpha$-internexin reduced/loss of expression than those with positive ones $(P=0.015$ and $P$ $=0.019$, respectively). However, methylation levels of other CpG sites were not associated with $\alpha$-internexin expression $(P>0.05)$.

In subtype of GI-NENs, the median methylation percentage of total CpG sites was higher in tumors with $\alpha$-internexin deficiency than that in tumors with $\alpha$-internexin expression $(68.5 \%$ vs. $61.8 \% ; P=0.011)$. The methylation level of each CpG site was also significantly higher in tumors with $\alpha$-internexin protein deficiency ( $P$ values range from 0.002 to 0.039 ). In subtype of pNENs, no associations between methylation levels of $\alpha$-internexin and protein expression were observed (the average of total $12 \mathrm{CpG}$ sites as well as each site were all examined) $(P>0.05)$. Major results of correlation between $\alpha$-internexin methylation status and protein expression are showed in Table 5. Full results are listed in Additional file 1: Table S1.

\section{Correlation of a-internexin methylation status with clinicopathological variables}

In patients with GEP-NENs, there were no correlation between $\alpha$-internexin methylation and clinicopathological features, such as tumor functional status, tumor location, tumor grade, tumor type and TNM stage. Similar results were also found in subtype of pNENs.

In subtype of GI-NENs, methylation level of total $12 \mathrm{CpG}$ sites was significantly higher in tumors of stage III + IV than that in stage I + II $(68.4 \%$ vs. 61 . $\left.7 \% ; X^{2}=5.847, P=0.016\right)$. Furthermore, methylation level of $\mathrm{CpG} \mathrm{S}_{8}$ was significantly associated with tumor grade $(P=0.033)$. Methylation levels of CpG $\mathrm{S}_{2} \sim \mathrm{S}_{4}, \mathrm{~S}_{6}$ and $\mathrm{S}_{8}$ were also significantly associated with tumor type ( $P$ values range from 0.014 to 0.036 ). Methylation levels of either site in CpG $S_{1} \sim S_{5}, S_{10}$ and $\mathrm{S}_{11}$ were significantly higher in advanced stage tumors ( $P$ values range from 0.018 to 0.044$)$. The association between clinicopathological features and $\alpha$-internexin methylation status in patients with GEPNENs, subtype of GI-NENs and pNENs are listed in Additional file 2: Table S2. 
Table 3 Association of a-internexin protein expression with clinicopathological variables

\begin{tabular}{|c|c|c|c|c|}
\hline Characteristics & $\mathrm{N}$ & $\begin{array}{l}\text { Reduced/loss } \\
\text { of expression (\%) }\end{array}$ & $x^{2}$ value & $P$ value \\
\hline \multicolumn{5}{|l|}{ GEP-NENs $(n=286)$} \\
\hline Functional status & & & 6.213 & 0.013 \\
\hline Nonfunctional & 234 & $179(76.5)$ & & \\
\hline Functional & 52 & $31(59.6)$ & & \\
\hline Tumor location & & & 2.356 & 0.308 \\
\hline Gastrointestinal tract & 162 & $124(76.5)$ & $2.340^{d}$ & $0.126^{d}$ \\
\hline Rectum & 60 & $32(53.3)$ & $43.470^{e}$ & $<0.001^{\mathrm{e}}$ \\
\hline Stomach & 43 & $42(97.7)$ & & \\
\hline Duodenum & 21 & 17(81.0) & & \\
\hline Esophagus & 18 & $18(100)$ & & \\
\hline Jejunum/ileum & 9 & $9(100)$ & & \\
\hline Appendix & 6 & $2(33.3)$ & & \\
\hline Colon & 5 & $4(80.0)$ & & \\
\hline Pancreas & 93 & $63(67.7)$ & & \\
\hline Other & 31 & $23(74.2)$ & & \\
\hline Tumor grade ${ }^{a}$ & & & 49.934 & $<0.001$ \\
\hline G1 & 120 & $69(57.5)$ & & \\
\hline G2 & 57 & $36(63.2)$ & & \\
\hline G3 & 101 & 99(98.0) & & \\
\hline Tumor type ${ }^{a}$ & & & 46.807 & $<0.001$ \\
\hline NET & 180 & $108(60.0)$ & & \\
\hline NEC + MANEC & 98 & $96(98.0)$ & & \\
\hline Tumor stage & & & 28.106 & $<0.001$ \\
\hline $1+\|$ & 140 & 83(59.3) & & \\
\hline$I I I+I V$ & 146 & $127(87.0)$ & & \\
\hline \multicolumn{5}{|l|}{ GI-NENs $(n=162)$} \\
\hline Tumor grade ${ }^{b}$ & & & 41.938 & $<0.001$ \\
\hline G1 & 60 & $31(51.7)$ & & \\
\hline G2 & 21 & $14(66.7)$ & & \\
\hline G3 & 75 & 74(98.7) & & \\
\hline Tumor type ${ }^{b}$ & & & 40.004 & $<0.001$ \\
\hline NET & 81 & 45(55.6) & & \\
\hline NEC + MANEC & 75 & 74(98.7) & & \\
\hline Tumor stage & & & 25.786 & $<0.001$ \\
\hline $1+\|$ & 74 & $43(58.1)$ & & \\
\hline$I I I+I V$ & 88 & $81(92.0)$ & & \\
\hline \multicolumn{5}{|l|}{ pNENs ( $n=93$ ) } \\
\hline Tumor grade ${ }^{c}$ & & & 2.929 & 0.231 \\
\hline G1 & 54 & $34(63.0)$ & & \\
\hline G2 & 27 & 19(70.4) & & \\
\hline G3 & 10 & $9(90.0)$ & & \\
\hline Tumor type ${ }^{c}$ & & & 1.080 & 0.299 \\
\hline NET & 84 & $56(66.7)$ & & \\
\hline
\end{tabular}

Table 3 Association of a-internexin protein expression with clinicopathological variables (Continued)

\begin{tabular}{lllll}
\hline Characteristics & $N$ & $\begin{array}{l}\text { Reduced/loss } \\
\text { of expression (\%) }\end{array}$ & X2 value & $P$ value \\
\hline NEC + MANEC & 7 & $6(85.7)$ & 4.638 & 0.031 \\
$\begin{array}{l}\text { Tumor stage } \\
\text { I+ II }\end{array}$ & 60 & $36(60.0)$ & & \\
III + IV & 33 & $27(81.8)$ & & \\
\hline
\end{tabular}

a 278 cases both for tumor grade and tumor type; ${ }^{\mathrm{b}} 156$ cases both for tumor grade and tumor type; ${ }^{c} 91$ cases both for tumor grade and tumor type; ${ }^{\mathrm{d}}$ The $X^{2}$ and $P$ value were computed by the contrast between gastrointestinal tract and pancreas; ${ }^{\mathrm{e}}$ The $\mathrm{X} 2$ and $P$ value were computed by the contrast among different sites of gastrointestinal tract

GEP-NEN: Gastroenteropancreatic neuroendocrine neoplasm; NET:

Neuroendocrine tumor; NEC: Neuroendocrine carcinoma; MANEC: Mixed adenoneuroendocrine carcinoma; GI-NEN: Gastrointestinal neuroendocrine neoplasm; pNEN: Pancreatic neuroendocrine neoplasm

\section{Correlation of a-internexin methylation status with overall survival}

A total of 116 patients with $\alpha$-internexin methylation detection received long-term follow up with a median duration of 3.53 years (range, 0.04-11.92 years). At the final followup, 30 patients $(25.9 \%)$ had succumbed to the disease.

In patients with GEP-NENs, first ROC curve was performed to achieve the suitable cutoff value (50\%), to define the methylation status of the examined region (Fig. 4a1). Patients were divided into higher $(\geq 50 \%)$ and lower $(<$ $50 \%) \alpha$-internexin methylation level groups. Kaplan-Meier analysis showed that no significantly statistical difference was found between $\alpha$-internexin methylation and patient survival. In subtype of GI-NENs and pNENs, univariate analyses also failed to reveal a significant association between $\alpha$-internexin methylation and tumor-related death. ROC curve and major results are showed in Fig. 4. Full results are listed in Additional file 3: Table S3.

\section{Discussion}

As a cytoskeleton protein, several lines of evidence have suggested that $\alpha$-internexin may play roles in the cell differentiation, the composition and development of intermediate filaments cytoskeleton, as well as in the tumor initiation and progression [4]. Previous studies showed that $\alpha$-internexin was frequently detected in medulloblastomas and neuroblastomas. The deficiency of $\alpha$-internexin was confirmed to be associated with malignant biological behaviors $[5,6,14]$. Until now, we know only little about the expression of $\alpha$-internexin in GEPNEN according to several previous studies. A small sample study revealed that the $\alpha$-internexin expression rate was $100 \%(12 / 12)$ in appendiceal well-differentiated NEN, while $50 \%(4 / 8)$ in rectal cases [8]. Liu B et al. detected 350 cases of pNEN showed that the reduced/loss of expression of $\alpha$-internexin was $46.6 \%$. In nonfunctional pNENs, the reduced/loss of $\alpha$-internexin expression was much higher than that in functional pNENs 

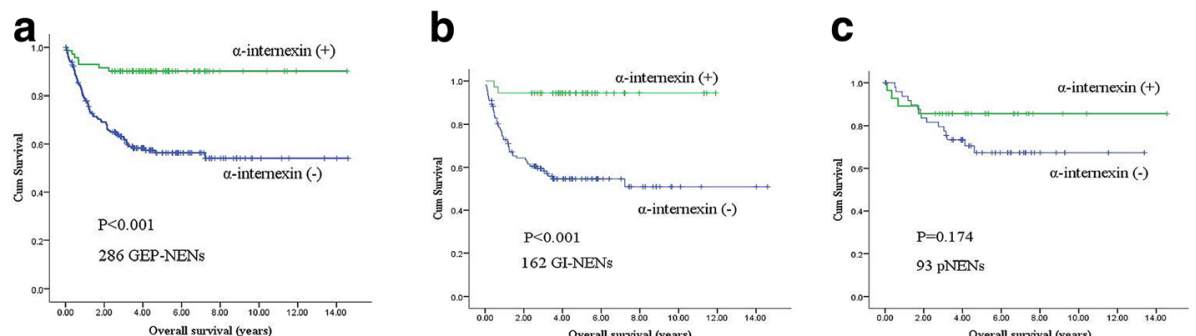

Fig. 2 Kaplan-Meier survival curves of patients with GEP-NENs and subtypes of GEP-NENs according to a-internexin expression. a Overall survival by a-internexin expression in GEP-NENs. b Overall survival by a-internexin expression in GI-NENs. c Overall survival by a-internexin expression in pNENs. GEP-NEN: Gastroenteropancreatic neuroendocrine neoplasm; GI-NEN: Gastrointestinal neuroendocrine neoplasm; pNEN: Pancreatic neuroendocrine neoplasm

(66\% vs. $32.5 \%, P=5.78 \times 10^{-10}$ ) [7]. However, these studies only focused on a single site of tumors (appendix, rectum or pancreas). In this study, we systematically examined the expression of $\alpha$-internexin in 286 cases of GEP-NEN tissues. We found that overall $\alpha$-internexin deficiency rate was $73.4 \%$. The reduced/loss of $\alpha$-internexin expression was significantly increased in tumors without hormonal syndrome, which was comparable to the results reported by Liu B. Furthermore, $\alpha-$ internexin deficiency percentage was slightly higher in GI-NENs $(76.5 \%, 124 / 162)$ compared with pNENs. The highest deficiency percentages of sites were the esophagus $(18 / 18,100 \%)$ and jejunum/ileum (9/9, 100\%), followed by stomach $(42 / 43,97.7 \%)$, duodenum $(17 / 21$, $81.0 \%)$, colon $(4 / 5,80.0 \%)$, rectum $(32 / 60,53.3 \%)$ and appendix $(2 / 6,33.3 \%)$, with significantly difference $\left(x^{2}=\right.$ 43.470, $P<0.001)$. Our results showed that $\alpha$-internexin expression demonstrates marked heterogeneity and differences in tumor sites.

Modlin et al. enrolled 50 pNENs and 42 SI-NENs showed that $\alpha$-internexin expression were significantly higher in G2 tumors and metastasis than G1 and primaries [9]. In contrast with the above results, Liu B et al. revealed that the reduced expression of $\alpha$ - internexin was significantly higher in metastasis (71. $8 \%$ vs. $34.5 \% ; P=1.97 \times 10^{-10}$ ). Tumors with G3 (only 9 cases) showed a higher $\alpha$-internexin deficiency rate (the reduced/loss of $\alpha$-internexin expression of tumors with G1, G2 and G3 were 47.3, 51.5 and $77.8 \%$, respectively), although no statistically significant difference was observed $(P=0.213)$ [7]. However, these previous studies mainly focused on well-differentiated endocrine tumors (G1 and G2). In the present study, in agreement with Liu B et al. 's findings, our results revealed that a gradual decline in the reduced/loss of $\alpha$-internexin expression in poorly- (tumors graded as G3 or classified as NEC + MANEC) and welldifferentiated tumors (G1, G2 or NET; both $P<0$. 001). In addition, $\alpha$-internexin expression deficiency was significantly higher in tumors of stage III + IV than stage I + II (87.0\% vs. $59.3 \% ; P<0.001)$. Similar results were found in subtype of GI-NENs. In subtype of pNENs, although no significant correlation was observed between $\alpha$-internexin expression and tumor differentiation, $\alpha$-internexin deficiency was higher in tumors with advanced stage $(P=0.031)$. Therefore, the current study indicated that the reduced/loss of $\alpha$ internexin was significantly associated with tumor

Table 4 Multivariate analysis of overall survival in patients

\begin{tabular}{|c|c|c|c|c|c|c|}
\hline \multirow[t]{2}{*}{ Factors } & \multicolumn{2}{|l|}{ GEP-NENs } & \multicolumn{2}{|l|}{ Gl-NENs } & \multicolumn{2}{|l|}{ pNENs } \\
\hline & $\mathrm{HR}(95 \% \mathrm{Cl})$ & $P$ value & $\mathrm{HR}(95 \% \mathrm{Cl})$ & $P$ value & HR $(95 \% \mathrm{Cl})$ & $P$ value \\
\hline Sex & $1.403(0.815-2.414)$ & 0.222 & $1.261(0.638-2.493)$ & 0.505 & $0.443(0.145-1.350)$ & 0.152 \\
\hline Age (years) at diagnosis & $1.332(0.753-2.357)$ & 0.325 & $1.404(0.763-2.585)$ & 0.275 & $0.373(0.081-1.727)$ & 0.207 \\
\hline Functional status & $1.048(0.352-3.120)$ & 0.932 & $1.300(0.137-12.375)$ & 0.820 & $0.657(0.155-2.789)$ & 0.569 \\
\hline Tumor location & $0.776(0.406-1.484)$ & 0.443 & - & - & - & - \\
\hline Tumor grade & $0.106(0.017-0.640)$ & 0.019 & $0.070(0.013-0.389)$ & 0.002 & $2.473(1.164-5.103)$ & 0.018 \\
\hline Tumor type & $0.468(0.115-1.903)$ & 0.289 & $6.531(2.602-16.392)$ & $<0.001$ & $1.705(0.233-12.472)$ & 0.599 \\
\hline Tumor stage & $0.201(0.083-0.489)$ & $<0.001$ & $3.800(1.522-9.487)$ & 0.004 & $21.083(2.503-177.556)$ & 0.005 \\
\hline a-internexin expression ${ }^{a}$ & $0.770(0.298-1.985)$ & 0.588 & $1.303(0.241-7.058)$ & 0.759 & 3.998 (0.935-17.092) & 0.062 \\
\hline
\end{tabular}

${ }^{a}$ a-internexin expression means reduced/loss of expression of a-internexin

GEP-NEN Gastroenteropancreatic neuroendocrine neoplasm; GI-NEN: Gastrointestinal neuroendocrine neoplasm; pNEN: Pancreatic neuroendocrine neoplasm. HR Hazard ratios, $\mathrm{Cl}$ Confidence intervals 

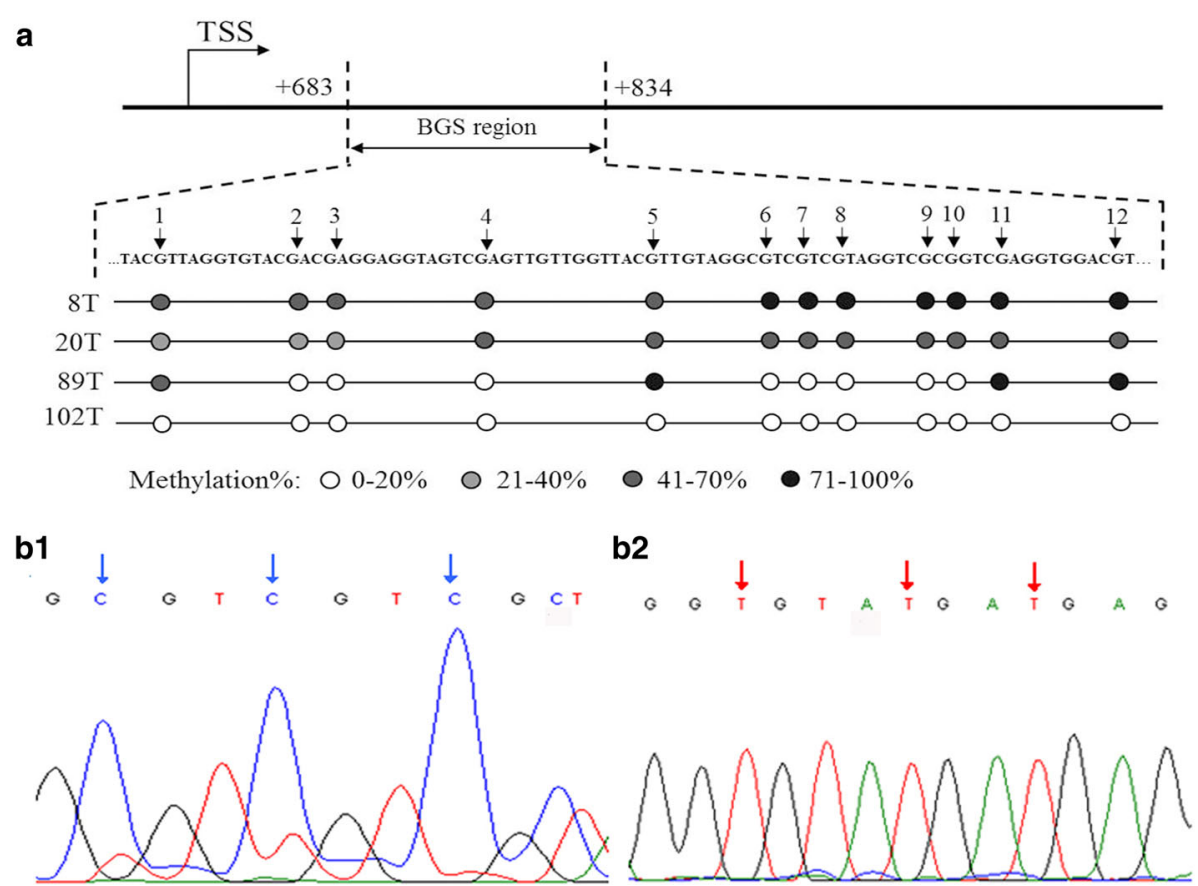

Fig. 3 Representative results of bisulfite genome sequencing for methylation analysis. a The bisulfite genome sequencing (BGS) analysis was performed on the $a$-internexin genomic region $(+683 \sim+834)$ relative to the transcription start site $(T S S)$. DNA sequence of the region for BGS and methylation level of CpG sites are shown. b1 Pancreas neuroendocrine tumor, G1, a-internexin positive expression, 3 CpG sites were unmethylated (red arrow). b2 Rectum neuroendocrine carcinoma, G3, loss expression of a-internexin, 3 CpG sites were methylated (blue arrow)

differentiation and stage, a decrease in $\alpha$-internexin expression with increasing malignancy in GEP-NEN.

Previous studies showed that expression of $\alpha$ internexin was correlated with better overall survival in gliomas $[15,16]$. Their findings are consistent with our observations that $\alpha$-internexin positive expression is a favorable prognostic marker. In our study, we found that the reduced/loss of expression of $\alpha$-internexin was significantly associated with a shorter survival time not only in GEP-NEN patients, but also in subtype of GINENs in univariate analyses, suggesting that $\alpha$ internexin deficiency was significantly associated with a shortened survival time of patients. However, multivariable analysis demonstrated that $\alpha$-internexin was not an independent prognostic marker. In pNEN patients, Liu $B$ et al. found that reduced/loss of expression of $\alpha$ internexin predicted worse survival [7], which was inconsistent with our study. In the present study, although no statistically difference, we observed a tendency towards poorer survival in pNEN patients with $\alpha$ internexin deficiency (mean OS: 9.8 vs. 12.6 years; $P=0$. 174). These findings suggested that patients with $\alpha$ internexin deficiency had a worse prognosis in GEPNENs.

It has been well-documented that hypermethylation of CpG islands in gene promoter could induce the transcriptional silencing of the gene [17-19]. Liu B et al. detected the methylation status of $\alpha$-internexin promoter $(-107 \sim 96$ region) by denaturing high-performance liquid chromatography in 17 pNENs and 8 paired tissues, found that hypomethylation of $\alpha$-internexin gene was associated with protein expression in vivo $(P=0.015)$ [7]. In contrast with the previous study, bisulfite sequencing of the $+683 \sim+834$ region of $\alpha$-internexin gene was examined in our study. Although the correlation of gene methylation level of total CpG sites with $\alpha$-internexin expression was not statistically significant in our GEPNEN cohort, further analysis with each CpG site found that two $\mathrm{CpG}$ sites $\left(\mathrm{S}_{4}\right.$ and $\left.\mathrm{S}_{6}\right)$ showed higher methylation levels in tumors without $\alpha$-internexin expression. Importantly, in subtype of GI-NENs, hypermethylation of this region was closely related with reduced/loss of expression of $\alpha$-internexin. The result was confirmed not only in the examination of total CpG sites but also in each examined site. Furthermore, several CpG sites including $S_{1} \sim S_{6}, S_{8} S_{10}$ and $S_{11}$ had higher methylation levels in tumors with poorly differentiated and advanced stage. However, in subtype of pNENs, we found that $\alpha$ internexin methylation was not associated with protein expression, and clinicopathological features, such as tumor functional status, grade, type and TNM stage. Therefore, we speculated that the regulatory region $(+$ $683 \sim+834)$ may be crucial for regulating $\alpha$-internexin expression in GI-NENs, but not in pNENs. Previous 
Table 5 Correlation of a-internexin methylation status with protein expression (major results)

\begin{tabular}{|c|c|c|c|c|}
\hline & Methylation level & & Z & $P$ \\
\hline & a-internexin (-) & a-internexin (+) & & \\
\hline GEP-NENs ( $n=116)$ & & & & \\
\hline Average of total $12 \mathrm{CpG}$ sites & $65.8(0-85.3)$ & $64.1(0-79.5)$ & 1.692 & 0.091 \\
\hline $\mathrm{S}_{4}$ & $63.3(0-80.8)$ & $57.8(0-73.5)$ & 2.424 & 0.015 \\
\hline $\mathrm{S}_{6}$ & $66.0(0-89.3)$ & $61.0(0-81.4)$ & 2.338 & 0.019 \\
\hline GI-NENs $(n=54)$ & & & & \\
\hline Average of total $12 \mathrm{CpG}$ sites & $68.5(0-81.7)$ & $61.8(11.5-67.8)$ & 2.539 & 0.011 \\
\hline$S_{1}$ & $53.2(0-100)$ & $45.8(12.6-61.8)$ & 2.062 & 0.039 \\
\hline $\mathrm{S}_{2}$ & $53.5(0-68.3)$ & $41.6(0-55.3)$ & 2.855 & 0.004 \\
\hline $\mathrm{S}_{3}$ & $50.0(0-67.3)$ & $41.3(0-52.6)$ & 2.633 & 0.008 \\
\hline $\mathrm{S}_{4}$ & $64.6(0-79.5)$ & $56.7(0-65.6)$ & 2.897 & 0.004 \\
\hline $\mathrm{S}_{5}$ & $65.6(0-85.7)$ & $62.1(11.5-76.3)$ & 2.094 & 0.036 \\
\hline$S_{6}$ & $67.4(0-89.3)$ & $56.0(0-68.0)$ & 3.130 & 0.002 \\
\hline $\mathrm{S}_{7}$ & $66.0(0-85.7)$ & $61.0(0-69.4)$ & 2.105 & 0.035 \\
\hline $\mathrm{S}_{8}$ & $82.9(0-93.8)$ & $70.3(0-84.1)$ & 2.583 & 0.010 \\
\hline $\mathrm{S}_{9}$ & $66.2(0-84.4)$ & $54.9(0-67.7)$ & 2.695 & 0.007 \\
\hline$S_{10}$ & $80.5(0-93.6)$ & $65.4(0-81.6)$ & 2.606 & 0.009 \\
\hline$S_{11}$ & $83.2(0-96.9)$ & $76.0(10.8-83.3)$ & 2.517 & 0.012 \\
\hline $\mathrm{S}_{12}$ & $78.6(0-88.2)$ & $66.6(13.2-79.0)$ & 2.595 & 0.009 \\
\hline pNENs ( $n=49$ ) & & & & \\
\hline Average of total $12 \mathrm{CpG}$ sites & $63.6(49.1-85.3)$ & $66.0(24.0-79.5)$ & 0.164 & 0.870 \\
\hline
\end{tabular}

$\mathrm{S}_{1}, \mathrm{~S}_{2} \ldots \mathrm{S}_{12}$ means each $\mathrm{CpG}$ site in the region (+ 729 +834) of a-internexin

GEP-NEN Gastroenteropancreatic neuroendocrine neoplasm, GI-NEN Gastrointestinal neuroendocrine neoplasm; pNEN: Pancreatic neuroendocrine neoplasm
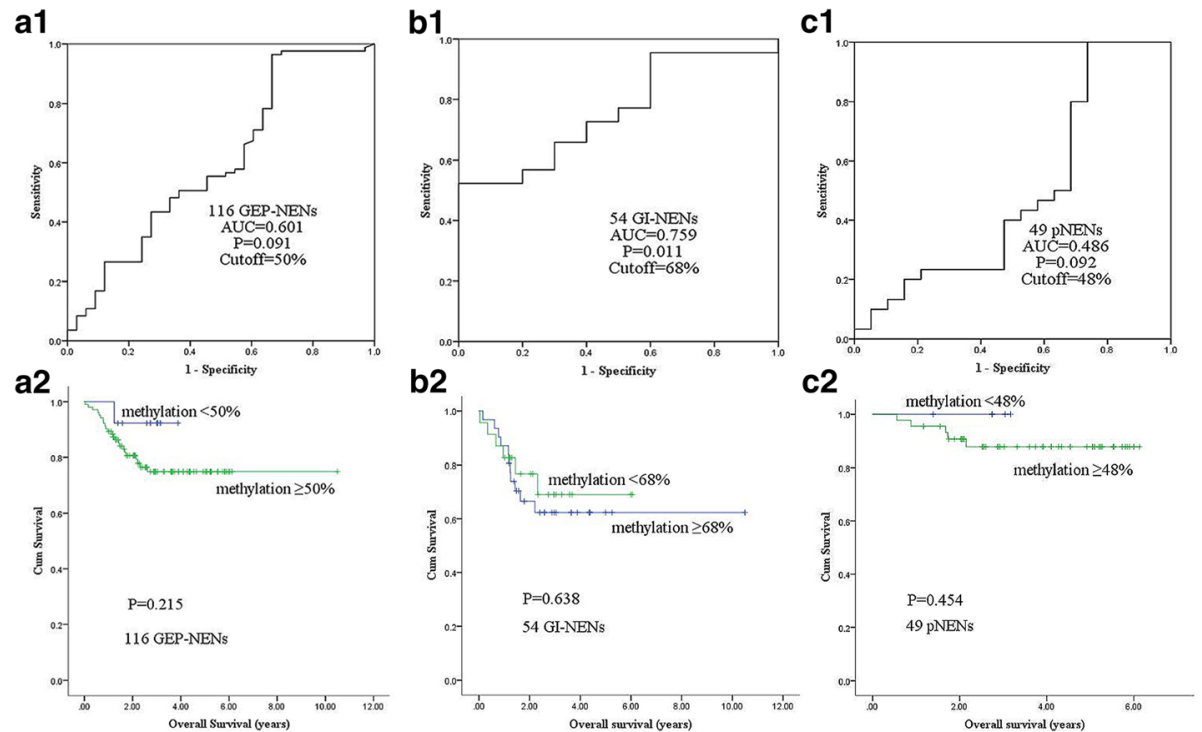

Fig. 4 Correlation of a-internexin methylation with overall survival. a1, b1, c1 Receiver operating characteristic (ROC) curve was used to determine a best cutoff value to define the methylation status of a-internexin in GEP-NENs, subtype of GI-NENs and pNENs. a2, b2, c2 Overall survival by ainternexin methylation (results were examined by methylation level of the average of total 12 CpG sites) in GEP-NENs, subtype of GI-NENs and pNENs. ROC: Receiver operating characteristic; AUC: Area under ROC curve; GEP-NEN: Gastroenteropancreatic neuroendocrine neoplasm; GI-NEN: Gastrointestinal neuroendocrine neoplasm; pNEN: Pancreatic neuroendocrine neoplasm 
study also reported a strong negative correlation between methylation and gene expression was found in downstream of the promoter up to $8 \mathrm{~kb}$ away [20], supporting our findings. In consequence, further demethylation studies are required to validate the role of the examined region in the regulatory of $\alpha$-internexin expression. Moreover, we found hypermethylation of most CpG sites in the region suggested more malignancy in GI-NEN.

Gene methylation has been reported as a promising predictive biomarker in many human cancers [21]. So far, the contribution of epigenetic changes to the prognosis of GEN-NENs is still largely unknown. In our study, we explored the prognostic value of $\alpha$-internexin methylation in GEP-NEN for the first time. We found a tendency towards shorter survival in patients with higher methylation level of $\alpha$-internexin. Similar results were also found in subtype of GI-NENs and pNENs. In GEP-NEN, the value of $\alpha$ internexin inactivation by gene methylation deserves further investigation. The prognostic role of $\alpha$-internexin methylation needs to be validated in systematically, prospective studies with a larger sample size.

\section{Conclusions}

The expression of $\alpha$-internexin was highly heterougeneous in different sites of GEP-NENs. The reduced/loss of expression of $\alpha$-internexin was closely related to tumors with aggressiveness and patient's adverse prognosis. The hypermethylation of the regulatory region examined may be an important epigenetic regulation mechanism of $\alpha$ internexin deficiency in subtype of GI-NENs.

\section{Additional files}

Additional file 1 Table S1. Correlation of a-internexin methylation status with protein expression. (DOCX $27 \mathrm{~kb}$ )

Additional file $\mathbf{2}$ Table S2. Correlation of a-internexin methylation status with clinicopathological variables. (DOCX $49 \mathrm{~kb}$ )

Additional file $\mathbf{3}$ Table S3. Correlation of $\alpha$-internexin methylation status with overall survival. (DOCX $28 \mathrm{~kb}$ )

\section{Abbreviations}

BGS: Bisulfite genomic sequencing; Cl: Confidence intervals; GEPNEN: Gastroenteropancreatic neuroendocrine neoplasm; GINEN: Gastrointestinal neuroendocrine neoplasm; HR: Hazard ratios; MANEC: Mixed adenoendocrine carcinoma; NEC: Neuroendocrine carcinoma; NET: Neuroendocrine tumor; OS: Overall survival; pNEN: Pancreatic neuroendocrine neoplasm; ROC: Receiver operating characteristic; TNM: Tumor-Node-Metastasis; TSS: Transcription starting site; ainternexin: Alpha-internexin

\section{Acknowledgements}

The authors wish to thank Qiuyue Wang (State Key Laboratory of Oncology in South China, Sun Yat-sen University Cancer Center) and Jing Guo (Department of Gastroenterology, the First Affiliated Hospital, Sun Yat-Sen University) for their skillful basic research assistance. The authors are grateful to Dr. Shaodong Hong (Department of Medical Oncology, Sun Yat-sen University Cancer Center) for skillful writing assistance.

\section{Funding}

This work was supported by the Guangzhou Science and Technology Foundation (201804010078).

\section{Availability of data and materials}

The data in the current study are maintained at the corresponding author, and will be further analyzed in authors' future study. Any reasonable request will be considered but all identifying patient data will be withheld and not be provided.

\section{Authors' contributions}

JC designed the study, YJC, YZ and LHC provided data, YHW, XXL and WMH performed the research, YHW analyzed the data and wrote the manuscript, $\mathrm{MHC}$ and JC critically reviewed the manuscript. All authors approved the final versions of the manuscript.

\section{Ethics approval and consent to participate}

The ethics approvals were provided by the institutional review board of The First Affiliated Hospital, Sun Yat-Sen University. All patients enrolled in this study provided written informed consent for the research study protocol. All methods were carried out in accordance with 1964 Helsinki declaration and its later amendments or comparable ethical standards.

\section{Consent for publication}

All respondents gave consent to publication of data.

\section{Competing interests}

The authors declare that they have no competing interests.

\section{Publisher's Note}

Springer Nature remains neutral with regard to jurisdictional claims in published maps and institutional affiliations.

\section{Author details}

${ }^{1}$ Department of Gastroenterology, The First Affiliated Hospital, Sun Yat-sen University, No.58 Zhongshan II Road, Yuexiu District, Guangzhou 510080, China. ${ }^{2}$ Department of Gastroenterology, Peking Union Medical College Hospital, Beijing, China. ${ }^{3}$ State Key Laboratory of Oncology in South China, Collaborative Innovation Center for Cancer Medicine, Sun Yat-sen University Cancer Center, Guangzhou, China. ${ }^{4}$ Department of Pathology, Sun Yat-sen University Cancer Center, Guangzhou, China.

Received: 26 September 2017 Accepted: 26 April 2018

Published online: 26 June 2018

\section{References}

1. Modlin IM, Oberg K, Chung DC, Jensen RT, de Herder WW, Thakker RV, Caplin M, Delle Fave G, Kaltsas GA, Krenning EP, et al. Gastroenteropancreatic neuroendocrine tumours. Lancet Oncol. 2008;9(1):61-72.

2. Garcia-Carbonero R, Capdevila J, Crespo-Herrero G, Diaz-Perez JA, Martinez Del Prado MP, Alonso Orduna V, Sevilla-Garcia I, Villabona-Artero C, Beguiristain-Gomez A, Llanos-Munoz M, et al. Incidence, patterns of care and prognostic factors for outcome of gastroenteropancreatic neuroendocrine tumors (GEP-NETs): results from the National Cancer Registry of Spain (RGETNE). Ann Oncol. 2010;21(9):1794-803.

3. Yao JC, Hassan M, Phan A, Dagohoy C, Leary C, Mares JE, Abdalla EK, Fleming JB, Vauthey JN, Rashid A, et al. One hundred years after "carcinoid": epidemiology of and prognostic factors for neuroendocrine tumors in 35,825 cases in the United States. J Clin Oncol. 2008;26(18):3063-72.

4. Zhao J, Liem RK. Alpha-Internexin and Peripherin: expression, assembly, functions, and roles in disease. Methods Enzymol. 2016;568:477-507.

5. Kaya B, Mena H, Miettinen M, Rushing EJ. Alpha-internexin expression in medulloblastomas and atypical teratoid-rhabdoid tumors. Clin Neuropathol. 2003;22(5):215-21.

6. Foley J, Witte D, Chiu FC, Parysek LM. Expression of the neural intermediate filament proteins peripherin and neurofilament-66/alpha-internexin in neuroblastoma. Lab Investig. 1994;71(2):193-9.

7. Liu B, Tang LH, Liu Z, Mei M, Yu R, Dhall D, Qiao XW, Zhang TP, Zhao YP, Liu $\mathrm{TH}$, et al. Alpha-Internexin: a novel biomarker for pancreatic neuroendocrine tumor aggressiveness. J Clin Endocrinol Metab. 2014;99(5):E786-95. 
8. Ishida M, Kushima R, Brevet M, Chatelain D, Okabe H. Co-expression of neuronal intermediate filaments, peripherin and alpha-internexin in human well-differentiated endocrine neoplasms (carcinoid tumors) of the appendix. Mol Med Rep. 2008:1(2):191-5.

9. Schimmack S, Lawrence B, Svejda B, Alaimo D, Schmitz-Winnenthal H, Fischer L, Buchler MW, Kidd M, Modlin I. The clinical implications and biologic relevance of neurofilament expression in gastroenteropancreatic neuroendocrine neoplasms. Cancer. 2012;118(10):2763-75.

10. Bosman FT, Carneiro F, Hruban RH, Theise ND, WHO. Classification of tumors of the digestive system. Lyon: IARC Press; 2010.

11. Rindi G, Kloppel G, Alhman H, Caplin M, Couvelard A, de Herder WW, Erikssson B, Falchetti A, Falconi M, Komminoth P, et al. TNM staging of foregut (neuro)endocrine tumors: a consensus proposal including a grading system. Virchows Arch. 2006:449(4):395-401.

12. Rindi G, Kloppel G, Couvelard A, Komminoth P, Korner M, Lopes JM, McNicol AM, Nilsson O, Perren A, Scarpa A, et al. TNM staging of midgut and hindgut (neuro) endocrine tumors: a consensus proposal including a grading system. Virchows Arch. 2007;451(4):757-62.

13. Amin MB, Edge SB, Greene FL, Byrd DR, Brookland RK, Washington MK, Gershenwald JE, Compton CC, Hess KR, Sullivan DC, et al. AJCC cancer staging manual. New York: Springer; 2017.

14. Ushijima T. Detection and interpretation of altered methylation patterns in cancer cells. Nat Rev Cancer. 2005;5(3):223-31.

15. Mokhtari K, Ducray F, Kros JM, Gorlia T, Idbaih A, Taphoorn M, Wesseling P, Hoang-Xuan K, Van den Bent M, Sanson M. Alpha-internexin expression predicts outcome in anaplastic oligodendroglial tumors and may positively impact the efficacy of chemotherapy: European organization for research and treatment of cancer trial 26951. Cancer. 2011;117(13):3014-26.

16. Ducray F, Mokhtari K, Crinière E, Idbaih A, Marie Y, Dehais C, Paris S, Carpentier C, Dieme MJ, Adam C, et al. Diagnostic and prognostic value of alpha internexin expression in a series of 409 gliomas. Eur J Cancer. 2011:47(5):802-8.

17. Taby R, Issa JP. Cancer epigenetics. CA Cancer J Clin. 2010;60(6):376-92.

18. Weber M, Hellmann I, Stadler MB, Ramos L, Paabo S, Rebhan M, Schubeler D. Distribution, silencing potential and evolutionary impact of promoter DNA methylation in the human genome. Nat Genet. 2007;39(4):457-66.

19. Esteller M. Epigenetics in cancer. N Engl J Med. 2008;358(11):1148-59.

20. Schultz MD, He Y, Whitaker JW, Hariharan M, Mukamel EA, Leung D, Rajagopal N, Nery JR, Urich MA, Chen H, et al. Human body epigenome maps reveal noncanonical DNA methylation variation. Nature. 2015; 523(7559):212-6.

21. Park YJ, Claus R, Weichenhan D, Plass C. Genome-wide epigenetic modifications in cancer. Prog Drug Res. 2011;67:25-49.

\section{Ready to submit your research? Choose BMC and benefit from:}

- fast, convenient online submission

- thorough peer review by experienced researchers in your field

- rapid publication on acceptance

- support for research data, including large and complex data types

- gold Open Access which fosters wider collaboration and increased citations

- maximum visibility for your research: over $100 \mathrm{M}$ website views per year

At BMC, research is always in progress.

Learn more biomedcentral.com/submissions 